\title{
Testing the liquidity preference hypothesis using survey forecasts
}

\author{
Jose Renato Haas Ornelas $^{\mathrm{a}, \mathrm{b}, *}$, Antonio Francisco de Almeida Silva Jr. ${ }^{\text {c,d }}$ \\ a Banco Central do Brasil, Brazil \\ ${ }^{\mathrm{b}}$ University of Miami, United States \\ c Banco Central do Brasil, Brazil \\ d Universidade Federal da Bahia, Brazil
}

\section{A R T I C L E I N F O}

\section{Article history:}

Received 22 May 2014

Received in revised form 20 March 2015

Accepted 2 April 2015

Available online 9 April 2015

\section{JEL classification:}

C58

E43

E58

G1

Keywords:

Liquidity preference hypothesis

Interest rates

Term premium

Survey forecast

\begin{abstract}
A B S T R A C T
We evaluate the liquidity preference hypothesis (LPH) for the term structure of interest rates in a different way. Instead of using bond returns as traditional approaches, we use interest rate surveys with market expectations in order to evaluate LPH. This approach allows us to disentangle the effect of the changes in interest rate expectations from the liquidity premium. We found empirical support for the LPH with Brazilian data using both traditional and survey methods. However, the evaluation with interest rate surveys gives a higher statistical confidence level than the traditional approach when we perform tests for term premium monotonicity.
\end{abstract}

(c) 2015 Elsevier B.V. All rights reserved.

\section{Introduction}

There is a vast research on the term structure of interest rates, and one of the oldest issues in this literature is the liquidity preference hypothesis ${ }^{1}$ ( $\left.\mathrm{LPH}\right)$. This hypothesis states that the term premium increases monotonically over time to maturity. This means that the expected returns on government securities should monotonically increase over time to maturity. One problem with the empirical investigations of the term premium is that it is not directly measurable. The yield of long-term bonds embeds the market expectations

\footnotetext{
* Corresponding author at: SBS Quadra 3, Bloco B - Asa Sul, Brasília, DF, Brazil.

E-mail address: jrenato.ornelas@globo.com (J.R.H. Ornelas)

${ }^{1}$ See McCulloch (1975), Fama (1984), Boudoukh et al. (1999) and Kessel (1965). It is worth mentioning that the literature on testing LPH uses mainly the US data.
} 
for future short-term interest rates plus a term premium. Both can vary over time, and it creates a challenge for isolating term premium on a time series. In order to disentangle short-term interest rate expectations from term premium in bond yields, traditional literature usually uses time series of ex-post returns (see, for instance, Fama, 1984 or Patton and Timmermann, 2010). However, these time series must be long enough to mitigate the effects that arise from variations in future short-term interest rate expectations and term premium, as well as measurement errors. Also, the presence or absence of a rare event in the sample time period may induce a bias when using ex-post returns, if the sample size is not long enough. ${ }^{2}$ The article of Elton (1999) describes the problems arising from the use of realized returns on asset pricing tests.

An alternative approach to investigate LPH is to use surveys with market expectations instead of using only data from security prices and returns. Several decades ago McCulloch (1975) mentioned this possible approach, but at that time the data were not reliable, nor long enough. Nowadays, data is no longer an issue. Kim and Orphanides (2007, 2012) and Swanson (2007) show how one can calculate the term premium using survey data for the US market. This approach mitigates problems from variations in the short-term interest rate expectation as we account for expectations in an explicit way. Therefore, we are able to isolate and extract the term premium from bond yields by using expectations of short-term interest rates over the bond life.

This paper uses this novel approach to test the monotonicity of the interest rate term premium, i.e., it aims to test if the LPH holds for the term structure of interest rates. Therefore, the main contribution of the paper is using interest rate surveys with market expectations in order to evaluate LPH, instead of relying on bond expost returns as the traditional literature. The strength of this approach is that it allows us to split the effect of interest rate expectation movements (expectation hypothesis) from the liquidity premium in a clearer procedure. The problems from variations in the short-term interest rate expectations are mitigated because we take expectations in an explicit way. The approach allows us to extract the term premium from bond yields by using expectations of short-term interest rates over bond life. To the best of our knowledge, we are the first to formally test LPH using survey data.

We measure the term premium and test LPH for the Brazilian term structure using a survey of market expectations for the Brazilian monetary policy interest rate decisions carried out by the Central Bank of Brazil. This survey covers more than ten years of daily observations, and is therefore a valuable and unique source of information. We also use data from Brazilian term structures of interest rates. With this dataset, our approach consists of using the market expectations for future short-term interest rates to calculate the term premium for maturities up to 12 months. Our analysis strongly supports that term premia monotonically increase over time to maturity during our sample period. The term premium increases between two and four basis points for each additional month of maturity. These pairwise increases are statistically greater than zero, no matter whether we tested it separately or jointly. The traditional method produces much higher term premia, but also much wider standard errors. This suggests that the survey method is more precise. Overall, we found strong support for the liquidity preference hypothesis in the Brazilian market using the survey method, and weaker evidence using the traditional method.

In order to use survey forecasts to calculate the term premium, we need to check for possible biases. Otherwise the bias may be "transmitted" to the term premium. If we have an upward bias on surveys, our term premium may be biased downward, and vice-versa. Our results show that survey forecasts are an unbiased estimator of future monetary policy interest rates for our sample period.

This paper is structured as follows: Section 2 reviews the literature on LPH testing; Section 3 describes the dataset; Section 4 describes the method for estimating term premium and presents some descriptive statistics; Section 5 shows some interesting results when we condition term premium structure to the slope of term structure; Section 6 formally tests for the monotonicity of the term premium structure; and Section 7 concludes.

\section{Literature review}

There are two fundamental hypotheses on interest rate term structures. According to the pure expectation hypothesis, the forward rates are unbiased estimates of future spot rates. A more general specification of the

\footnotetext{
${ }^{2}$ This is related to the so-called peso-problem, which is the effect on statistical inference caused by a very low-probability event that do not occur in the sample.
} 
expectation hypothesis states that forward rates are the expectations of future spot rates plus a liquidity premium. Therefore, the difference between the yield of a long-term bond and the market's expectation of the future short-term rate is the liquidity or term premium ${ }^{3}$ (McCulloch, 1975). The liquidity preference hypothesis implies that the longer the term to maturity of a security, the higher its term premium. Therefore, the term structure of interest rates may be seen as the result of the combination of the expectations and liquidity preference hypotheses (Kessel, 1965).

The term premium may also be defined as the expected return of holding a government bond for one period minus the return of a one-period bond. The LPH would imply that the ex-ante return on government bond should monotonically increase over time to maturity (Boudoukh et al, 1999). As highlighted by Kim and Orphanides (2007), these distinct definitions of the term premium have the same intuition.

There are many procedures to evaluate the expectation hypothesis such as those in Campbell and Shiller (1991), Hardouvelis (1994) and Engle et al. (1987). However, the dynamics of the interest rate term structure is a conundrum. Empirical tests are liable to sample errors, measurement errors and changes in the level and variance of spreads. Hardouvelis (1994) discussed two possible mechanisms to explain changes in the interest rate term structure. The first one assumes that risk premia are constant and long rate movements may be sluggish relative to the movements of the current short rates. On the other hand, it would also be possible that markets overreact to a central bank announcement raising future spot rates by more than necessary and making spreads between long and short rates higher than they should be. This explanation therefore considers that the market's expectations violate rational expectations. The second mechanism considers that the market's expectations are rational but the information in the spread is composite information about the variation of both expected future rates and risk premia.

One issue investigated by Kessel (1965) was the changes in liquidity premium in time. The liquidity premium can vary with the level of interest rates or can vary with the economic cycle. The author found evidence in favor of the liquidity premium as a function of the level of interest rates. On the other hand, McCulloch (1975) discussed some research refuting this relationship and found no empirical support for this assumption.

The liquidity preference hypothesis states that the premium increases monotonically with maturity. Fama (1984) found empirical evidence for the liquidity preference hypothesis in shorter maturities, up to seven months. Nevertheless, the author argues that it is not possible to generalize this issue to longer maturities. McCulloch (1987) pointed out that there was a problem in the data sample with the selected time window due to the bid-ask spreads for the nine and ten month maturity in Fama's work. As a result, McCulloch gave empirical evidence for the premium increasing monotonically with maturity. Richardson et al (1992) used a test of inequality constraints proposed by Wolak (1989) and their general results support the work of McCulloch (1987). Boudoukh et al (1999) reinvestigated Fama's (1986) work and they showed that it is important to evaluate the joint inequality constraints and the type of conditioning information used in the estimate. Their findings, using a procedure similar to Wolak's (1989), are consistent with the liquidity preference hypothesis. Patton and Timmermann (2010) evaluated the liquidity preference hypothesis by inspecting the term premia on T-Bills from 1964 to 2001. Regarding monotonicity, the Wolak test rejects the hypothesis of increasing term structure, while the monotonic relation (MR) test of Patton and Timmermann fails to find evidence in favor of a monotonically increasing term structure.

The above authors relied on ex-post bond returns in order to evaluate the liquidity preference hypothesis and basically they considered that the differences between long and short maturity bond returns are due to the liquidity premium. For instance, Patton and Timmermann (2010) measured the term premium $\left(p_{t}^{k}\right)$ in the following way:

$$
p_{t}^{k}=E\left[r_{t}^{k}\right]-E\left[r_{t}^{1}\right]
$$

where $E\left[r_{t}^{k}\right]$ is the expected one-period ${ }^{4}$ return on a bond with maturity $k$, at time $t ; p_{t}^{k}$ is the term premium at time $t$, for a maturity $k$.

\footnotetext{
${ }^{3}$ We use "liquidity premium" and "term premium" as synonyms.

${ }^{4}$ This one-period return is usually set to one-month.
} 
On their empirical verification of the LPH, they estimated the expected return using monthly ex-post returns. Based on this set-up, the LPH implies that:

$$
p_{t}^{k}>p_{t}^{l} \text { for } k>l \text {. }
$$

Let us define $\Delta_{t}^{k}=p_{t}^{k}-p_{t}^{k-1}$ as being the difference between the term premium of two adjacent terms. We may rewrite Eq. (2) with only the adjacent terms:

$$
\Delta_{t}^{k}>0 \text { for all } k^{\prime} \mathrm{s} .
$$

Instead of using bond returns, several authors use interest rate surveys to estimate the term premium and then evaluate the expectation hypothesis. This is the case of Friedman (1979), Froot (1989), Cook and Hahn (1990), MacDonald and Macmillan (1994), and Jongen et al. (2011). Nevertheless, no paper so far has formally tested the LPH using survey data.

Kim and Orphanides (2012) use survey forecasts of the short-term interest rate to improve results in the estimate of a three-factor pure-Gaussian model and the authors argue that problems encountered in "conventional" estimation without survey data are greatly alleviated. Therefore the model reproduces the well-known pattern of deviation from the expectation hypothesis regressions and generates an implied forecast of long-term interest rates that captures some of the deviations of survey forecasts of long-term interest rates from the expectation hypothesis. The authors also show evidence that documents the presence of a substantial bias and imprecision in the parameter estimates in the conventional estimation and the improvement brought by estimating with survey data. They discuss the importance to a dynamic term structure of a persistent factor with a long half-life longer than 5 years. Furthermore, they highlight that surveys are prone to some measurement error, for example due to differences in the information sets and precise timing when various participants may prepare their responses and therefore it is important to allow for the possible presence of substantial errors when using information from surveys.

It is worth mentioning that literature regarding LPH is concentrated on the US data and therefore our paper contributes to empirical research in emerging market literature as we deal with Brazilian term structure.

\section{Sample}

Brazil has an inflation target regime and a floating exchange rate regime since 1999. The Central Bank of Brazil has been conducting surveys of analysts' forecasts of several financial and macroeconomic variables since December 2001. The forecasts come from different types of institutions, such as banks, brokers and consulting firms. One of the surveyed variables is the target for the monetary policy one-day interest rate which is called the Selic target rate. This target is set by the Brazilian monetary policy committee (Copom) at regular meetings. Up to the year 2005 these meetings were held every month, with intervals of four or five weeks. After 2006, the periodicity changed to every 45 days approximately, with intervals of 6 or 7 weeks. The meetings start on Tuesdays and finish on Wednesdays with the announcement of the target interest rate decision.

The Open Market Department of the Central Bank of Brazil is responsible for keeping the effective monetary policy interest rate (Selic rate) near the target set by Copom. The Selic rate is calculated based on one-day repo operations, using Brazilian Treasury Bonds as collateral. However, the effective rate is not exactly the same as the target rate, rather it oscillates some basis points around it.

Our sample has the daily data of the survey forecasts for the Selic target rate from 12 months to 18 months ahead. As the year of 2002 was very turbulent, including extraordinary meetings of Copom, we decided to exclude forecasts done in 2002 for the year of 2003. Thus, our sample starts with forecasts done in 2003 for the year of 2004. We have considered 86 Copom meetings from January, 21st 2004 to August 28th 2013. We limit the sample to 12-month forecasts to create a homogenous dataset, as 18 month forecasts are not available for the entire period. Forecasts are available on a daily basis, and a bulletin published every Friday night consolidates the results. We are the first to use such a detailed setup with interest rate surveys for $\mathrm{LPH}$ test. This is especially important when there is one or more monetary policy meetings in-between the three-month periods. 
We evaluate the liquidity preference hypothesis with the interbank market interest rate term structure, which is the most liquid instrument in the Brazilian Fixed Income market. Besides the survey forecasts, we used daily time series for the Selic target rate set by Copom, and the one-day interbank rate, which is the uncollateralized interbank deposit rate used as a benchmark index by most mutual funds and certificate of deposits. We also used an interbank zero-coupon yield curve. The zero-coupon curve was built with the one-day interbank fixed-to-floating swaps with maturities from 1 to 12 months. We assume that the interbank and the target Selic rate have a fixed spread, estimated based on the past data.

\section{Estimation of the term premium}

We can break down the yield of a zero-coupon bond into two components, the ex-ante term premium and the expected compounded short-term interest rates until the maturity of the bond, as follows:

$$
y_{t}^{k}=E_{t}\left[d_{t, k}\right]+p_{t}^{k}
$$

Where:

$y_{t}^{k} \quad$ is the annualized yield at time $t$ of a zero-coupon bond with maturity $k$ on the interbank curve;

$E_{t}\left[d_{t, k}\right]$ is the expected one-day effective interbank interest rate compounded from time $t$ to time $k$, and then expressed in annualized terms (see Eq. 1);

$p_{t}^{k} \quad$ is the annualized ex-ante interbank term premium at time $t$ for a $k$ maturity.

Therefore, ex-ante term premium $p_{t}^{k}$ can be calculated as the difference between the yield of a bond and the expected one-day rate for the same maturity $k$.

We used our method to estimate the term premia using daily data so as not to miss any policy interest rate (actual or expected) change. In order to calculate the term premium $p_{t}^{k}$ in Eq. (4), we need $y_{t}^{k}$ which is directly observable from the interbank swap curve and the expected one-day effective interbank interest rate compounded for a given maturity, $E_{t}\left[d_{t, k}\right]$. This latter term is calculated from the survey forecasts and from the spread between the interbank and target policy rates, as we see in Appendix A.

One relevant issue in our method is to assure that the survey has unbiased estimates of the target policy rate. If there is a bias in this estimate, it may contaminate the term premium estimation. An upward bias may decrease the term premium and vice-versa. Appendix B performs this test, and results show that the survey provides unbiased estimates for the future target policy rate.

We also calculated the term premium using the traditional method, which uses the ex-post returns of bonds. Graph I shows the means for term premia using both methods. For the survey method, all premia are positive and statistically significant, except for the one-month term premium, which is positive but not statistically significant. For the traditional method, although the premia are positive and higher than using the survey method, only the maturities from 1 to 5 are statistically significant.

Graph 1 also shows the confidence intervals. We see that average term premia monotonically increase as predicted by LPH, for both methods. We will test this issue formally in Section 6 . The confidence intervals of the survey method are in general tighter. In most of the maturities, the confidence interval of the survey method lies entirely inside the confidence interval of the traditional method. This suggests that the survey method is able to measure the premium with more precision. This is expected as the traditional method absorbs errors coming from time-varying short-term rate expectations and premia. In our sample, these errors are likely to foster an upward bias on the premium calculated using the traditional method because there was a slightly downward trend on both premia and expectations of short-term rates. In fact, the premia using the traditional methods are higher, as we can see in Graph 1.

Graph I also suggests that term premium is a positive linear function of time to maturity. In fact, linear regressions of term premium and time to maturity on a daily basis show that nearly $80 \%$ of the linear coefficients are positive and statistically significant at $5 \%$, for the survey method (see Table 1 ). This is further evidence in favor of a monotonically increasing ex-ante term premium. However, when using the traditional method the results are not so strong, with only half of the days having a term premia curve with a positive statistically significant slope. 


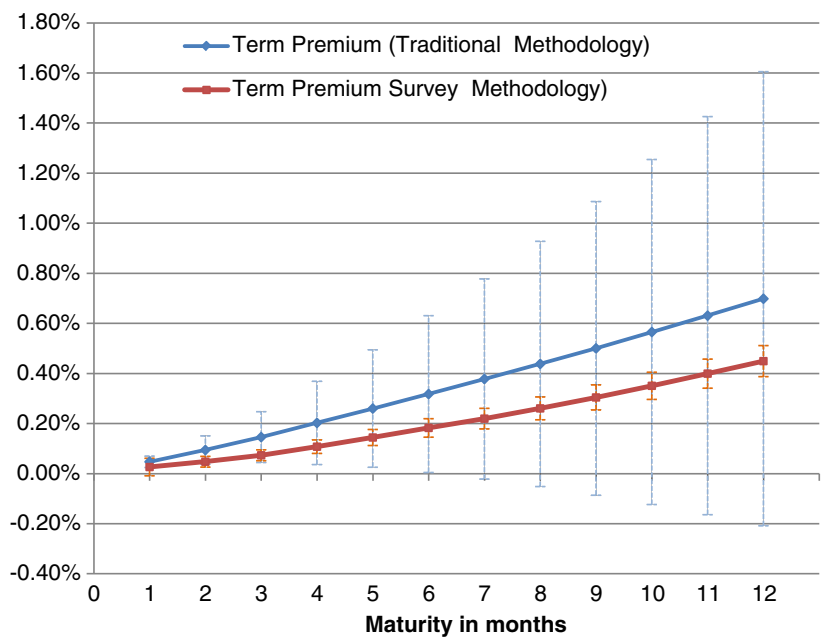

Graph 1. Average term premium. This graph shows the mean of the term premium $\left(p_{t}^{m}\right)$ calculated using both traditional and survey methods. It shows the mean term premium for maturities ranging from 1 to 12 months. It also shows the confidence intervals using $t$ statistics calculated with 8-lags Newey-West standard errors. Term premia are on an annualized basis.

We now analyze the behavior of the term premia over time. Graph 2 shows the variation in the term premium over the sample period, using the survey method. We can see some spikes, e.g. the 2008 crisis. Graph 2 suggests that the term premium measure shown here should be treated with some smoothing filter.

\section{Conditioning term premium to spot term structure slope}

One empirical issue reported by Fama (1986) is that the slope of the term structure may influence the slope of the term premia structure. In his findings, monotonicity of the term premium disappears when the term structure is inverted, which is evidence against the LPH. If LPH holds, the term premium should monotonically increase with time to maturity, no matter the slope of the yield curve. Boudoukh et al (1999) revisited Fama's (1986) findings using various econometric techniques, but found no evidence against LPH.

In order to investigate this issue, we fit linear regressions of bond yield $(y)$ and time to maturity $(m)$, for each day $t$. The results in Table 2 show that downward slopes are very frequent in the sample. The number of days with a statistically significant negative slope is approximately the same as those with a

Table 1

Slope of the ex-ante premium term structure.

\begin{tabular}{llc}
\hline Percentage of days with & Method & Survey \\
\cline { 2 - 3 } & Traditional & $79.9 \%$ \\
\hline Positive slope & $53.9 \%$ & $20.1 \%$ \\
Negative slope & $46.1 \%$ & $64.9 \%$ \\
Statistically significant positive slope & $50.9 \%$ & $12.6 \%$ \\
Statistically significant negative slope & $44.3 \%$ & $22.5 \%$ \\
Slope statistically equal to zero & $4.8 \%$ & \\
\hline
\end{tabular}

This table shows results of linear regressions of the term premium $\left(p_{t}^{m}\right)$ against time to maturity $m$, measure in months. We run the following regression for each day t of the sample: $p_{t}^{m}=\alpha_{t}+\beta_{t} m$. Each regression has 12 data points. This is done for both traditional and survey methods. The coefficient $\beta_{t}$ measures the slope of the premium term structure. Results show the percentage of the days that have positive and negative $\beta$, percentage of the days with statistically significant, at $5 \%$, positive and negative $\beta$, and percentage of the days with $\beta$ statistically equal to zero, also at $5 \%$. Time to maturity $m$ ranges from one to 12 months. 


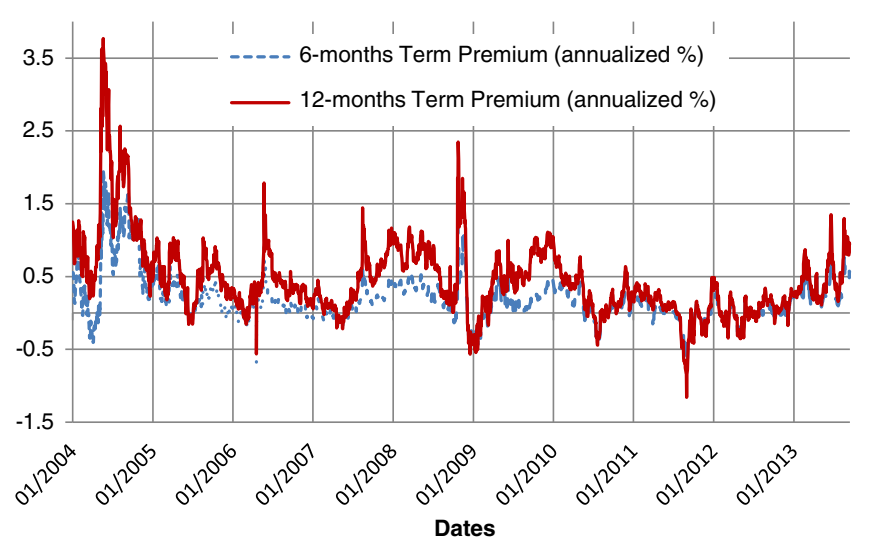

Graph 2. Term premium.

statistically significant positive slope. The reason is the downward trend in the Brazilian interest rates during the sample. Therefore, even with frequent inverted term structure, we find monotonically increasing term premium.

We investigate further this issue through an additional robustness test. We check if the results in Table 1 (i.e., monotonicity of term premium) remain the same even if we consider only the days with a downward sloping spot term structure. We then re-calculate the results in Table 1 conditional on a negative slope of the yield curve, i.e., we consider only the $45.1 \%$ of the days from Table 2 where the month's coefficient is statistically negative. Results are in Table 3 . We can see that they are qualitatively the same as in Table 1 . Hence, we may say that there is no evidence of the bias found by Fama (1986) in our results, coming from the negative slopes of the spot yield curve.

\section{Tests for monotonicity of term premium}

In this section, we formally test if term premia monotonically increase with time to maturity. First, we test if the term premium of month $m$ is higher than the term premium of month $m-1$. We may also view this as a test if the difference of the term premium of two consecutive months is greater than zero:

$$
\Delta_{t}^{m}=p_{t}^{m}-p_{t}^{m-1}>0
$$

Table 2

Slope of the spot term structure.

\begin{tabular}{ll}
\hline Percentage of days with & \\
\hline Positive slope & $54.9 \%$ \\
Negative slope & $45.1 \%$ \\
Statistically significant positive slope & $41.3 \%$ \\
Statistically significant negative slope & $41.7 \%$ \\
Slope statistically equal to zero & $17.0 \%$ \\
\hline
\end{tabular}

This table shows results of linear regressions of the yield $\left(y_{t}^{m}\right)$ against time to maturity $m$, measured in months. We run the following regression for each day t of the sample: $y_{t}^{m}=\alpha_{t}+\varphi_{t} m$. Each regression has 12 data points. The coefficient $\varphi_{t}$ measures the slope of the spot term structure. Results show the percentage of days that have positive and negative $\varphi$, percentage of days with statistically significant, at $5 \%$, positive and negative $\varphi$, and percentage of days with $\varphi$ statistically equal to zero, also at $5 \%$. Time to maturity $m$ ranges from one to 12 months. 
Table 3

Slope of the premium term structure conditional on a downward yield curve.

\begin{tabular}{lcc}
\hline Percentage of days with & Method & Survey \\
\cline { 2 - 3 } & Traditional & $81.4 \%$ \\
\hline Positive slope & $58.4 \%$ & $18.6 \%$ \\
Negative slope & $41.6 \%$ & $72.9 \%$ \\
Statistically significant positive slope & $53.9 \%$ & $18.4 \%$ \\
Statistically significant negative slope & $39.9 \%$ & $8.7 \%$ \\
Slope statistically equal to zero & $6.2 \%$ & \\
\hline
\end{tabular}

This table shows statistics of the slope of term premium (as in Table 1) conditional on negative slope of the spot yield curve, i.e., negative slope of Table 2. First, we run the spot yield curve slope regression: $y_{t}^{m}=\alpha_{t}+\varphi_{t} m$. Each regression has 12 data points. We run this regression for each day $t$ of the sample, and select those days where the coefficient $\varphi_{t}$ is negative, i.e., days with inverted yield curves. For these selected dates, we run the term premium slope regression: $p_{t}^{m}=\alpha_{t}+\beta_{t}^{*} m$. Each regression has 12 data points. This is done for both traditional and survey methods. The coefficient $\beta_{t}^{*}$ measures the slope of the premium term structure. Results show the percentage of the days that the term premium slope $\beta_{t}^{*}$ is positive and negative. It also shows percentage of the days with statistically significant positive and negative term premium slope and percentage of the days with statistically equal to zero, all at $5 \%$. Time to maturity $m$ ranges from one to 12 months.

Where:

$p_{t}^{m} \quad$ is the term premium of month $m$ at time $t$

$\Delta_{t}^{m} \quad$ is the difference of the term premium of two consecutive months $m$ and $m-1$ at time $t$.

Table 4 shows the descriptive statistics of $\Delta_{t}^{m}$ time series for $m$ varying from 2 to 12 months during our sample period calculated using traditional and survey methods. Results using the traditional method show very weak evidence in favor of $\mathrm{LPH}$. On the other hand, the results from using the survey method show that in all cases we can reject the null hypothesis that $\Delta_{t}^{m}$ is equal to zero with $5 \%$ significance. Therefore, we have very strong evidence in favor of the LPH using the survey method.

Data from Table 4 shows an average increase of 3.8 basis points for each additional month of maturity using the survey method, and 5.9 basis points using the traditional one.

The above procedure tests monotonicity independently for each pair of adjacent months. We could also jointly test if premia monotonically increase, i.e. $\Delta_{t}^{m}>0$ for all $m$ 's together.

Table 4

Term premium difference $\left(\Delta_{t}^{m}\right)$ statistics.

\begin{tabular}{llllr}
\hline \multirow{2}{*}{ \# of months $(\mathrm{m})$} & \multicolumn{2}{l}{ Traditional method } & & \multicolumn{2}{c}{ Survey method } \\
\cline { 2 - 4 } & Mean & t statistics & Mean & t statistics \\
\hline 2 & 0.047 & 2.49 & 0.021 & 2.35 \\
3 & 0.051 & 1.92 & 0.026 & 6.59 \\
4 & 0.057 & 1.44 & 0.034 & 7.55 \\
5 & 0.057 & 1.40 & 0.037 & 10.26 \\
6 & 0.058 & 1.26 & 0.038 & 11.28 \\
7 & 0.060 & 1.19 & 0.037 & 12.39 \\
8 & 0.060 & 1.15 & 0.041 & 13.94 \\
9 & 0.062 & 1.11 & 0.044 & 14.97 \\
10 & 0.065 & 1.08 & 0.046 & 16.24 \\
12 & 0.065 & 1.05 & 0.049 & 18.04 \\
\hline
\end{tabular}

This table shows the statistics of the difference between two adjacent months term premia $\Delta_{t}^{m}=p_{t}^{m}-p_{t}^{m-1}$ calculated by both traditional and survey methods. It shows the mean term premium difference for $m$ ranging from 2 to 12 months. It also shows the $t$ statistics calculated with 8-lags Newey-West standard errors for the null hypothesis that the term premium difference is equal to zero. Premia are on an annualized basis. 
In order to evaluate monotonicity we follow two procedures of testing for inequality constraints. The first one is presented by Wolak (1989). The null hypothesis is that all the estimated $\Delta$ are jointly greater than zero:

$$
H_{0}: \Delta \geq 0
$$

$\hat{\Delta}=\Delta+\nu, \nu$ is a $(\mathrm{N} \times 1)$ vector that is $\mathrm{N}(0, \Omega)$.

And $\Omega$ is of full rank $N$ and known. Wolak built the likelihood ratio statistic for this problem as the optimal value of the objective function from:

$$
\min _{\Delta}(\hat{\Delta}-\Delta)^{\prime} \Omega^{-1}(\hat{\Delta}-\Delta)
$$

Wolak defined $\hat{\Delta}$ as the solution of the likelihood ratio statistic problem and IU as the shorthand for the null hypothesis of inequality constraints versus an unrestricted alternative:

$$
I U=(\hat{\Delta}-\widetilde{\Delta}) / \Omega^{-1}(\hat{\Delta}-\widetilde{\Delta}) .
$$

The distribution of the likelihood ratio statistic satisfies:

$$
\sup _{\Delta \geq 0} \operatorname{Pr}_{\Delta, \Omega}[I U \geq c]=\sum_{k=0}^{N} \operatorname{Pr}\left[\chi_{k}^{2} \geq c\right] w(N, N-k, \Omega) .
$$

Where:

$N \quad$ is the number of restrictions.

The weight $w(N, N-k, \Omega)$ is the probability that $\hat{\Delta}$ has exactly $N-k$ positive elements. This weight is calculated by Monte Carlo simulation. The covariance matrix of the estimated parameters $\Omega$ may be calculated by the Newey and West (1987) procedure in order to correct to heteroskedasticity and autocorrelation.

The other procedure we use to test for inequality constraints is presented by Patton and Timmermann (2010). The authors defined the monotonic relation as MR and the null hypothesis in a different way than that presented above. The alternative hypothesis is that one the researcher wants to prove:

$$
\begin{aligned}
& H_{0}: \Delta \leq 0 \\
& H_{1}=\min _{i=1, \ldots, N} \Delta_{i}>0 .
\end{aligned}
$$

The statistic to be tested is:

$$
J_{T}=\min _{i=1, \ldots, N} \hat{\Delta}_{i}
$$

The estimated parameter vector $\hat{\Delta}$ asymptotically follows a normal distribution $\mathrm{N}(0, \Omega)$. Therefore the full set of the covariance matrix for the sample moments is necessary. The objective is to achieve the minimum value of a multivariate vector of estimated parameters and there are no tabulated critical values for such minimum values. Patton and Timmermann applied the stationary bootstrap procedure (Politis and Romano, 1994) in the returns and a Monte Carlo simulation to implement the MR test.

It is worth noting that Wolak and Patton-Timmermann tests have inverted null hypothesis. While in Wolak the null hypothesis is that LPH holds, in the Patton-Timmermann approach the null hypothesis is that LPH does not hold.

Patton and Timmermann (2010) also proposed a test considering all pairs of maturity, and not only adjacent months. In this way the deltas would be calculated for all combinations of the 12 maturities that we have in our case. 
We have performed these joint tests on our sample, and the results are in Table 5. The results obtained using the survey method strongly support LPH as the p-value for the Wolak test is very high and its null hypothesis is that LPH holds, and p-values for the Patton-Timmermann tests are under $1 \%$, and its null hypothesis is that LPH does not hold. For the traditional method, the Wolak test result supports LPH, and for the Patton-Timmermann tests, the p-values of $4 \%$ and $3.5 \%$ provide some mild evidence in favor of $\mathrm{LPH}$.

\section{Final remarks}

This paper uses a novel approach to test the liquidity preference hypothesis for the term structure of interest rates. Instead of using bond returns as the traditional approaches in the literature, we use interest rate surveys with market expectations in order to evaluate LPH. This approach allows us to split the effect of interest rate expectation movements (expectation hypothesis) from the liquidity premium in a clearer procedure. Thus, it mitigates problems from variations in the short-term interest rate expectations because we are accounting for expectations in an explicit way. As a result, we are able to extract the term premium from bond yields by using expectations of short-term interest rates over bond life.

We found empirical support for the LPH working with Brazilian interest rate data with both traditional and survey methods. Our analysis with survey information strongly supports the idea that term premia monotonically increase with time to maturity. The term premium increases between two and four basis points for each additional month of maturity. These pairwise increases are statistically greater than zero, no matter how we test it, separately or jointly. The traditional method produces much higher term premia, but also much wider standard errors. This suggests that the survey method is more precise. Furthermore, although there is some statistical evidence supporting LPH using the traditional method, the statistical evidence is much weaker than that found using the survey method.

The survey approach used in this paper may be used to evaluate the market sentiment regarding future steps in momentary policy. It also may be used to estimate the premium required by the market on Treasury bonds and bill auctions. In both cases, the levels of risk, uncertainty and disagreement for the future steps of the monetary and economic policies should affect the term premium.

This paper also opens the debate of testing LPH with survey data. We suggest the application of the interest rate surveys with market expectations in order to evaluate LPH for further studies on emerging markets, when enough data become available.

\section{Acknowledgments}

This paper should not be reported as representing the views of the Banco Central do Brasil. The views expressed in the papers are those of the authors and do not necessarily reflect those of the Banco Central do Brasil.

We would like to thank useful comments from Aquiles Farias and Sandro Andrade.

This paper was written while José Renato Haas Ornelas was a post-doctoral fellow at University of Miami.

Table 5

Joint tests of term premium differences.

\begin{tabular}{llll}
\hline Method & Wolak & $\begin{array}{l}\text { Patton-Timmermann } \\
\text { (adjacent maturities) }\end{array}$ & $\begin{array}{l}\text { Patton-Timmermann } \\
\text { (all pairs of maturities) }\end{array}$ \\
\hline Survey & 0.723 & 0.003 & 0.003 \\
Traditional & 0.248 & 0.040 & 0.035 \\
\hline
\end{tabular}

This table shows the p-value for three joint tests of monotonicity of term premia. The Wolak test has a null hypothesis that the term premia differences are jointly greater than zero. The Patton-Timmermann test has a null hypothesis that the term premia differences are jointly lower than zero. The Patton-Timmermann has two versions: one considering only adjacent maturities, and another considering all combinations of the 12 maturities, two by two. 


\section{Appendix A. Methodology for expected short-term interest rate}

We describe below how to calculate the expected short-term interest rate for the Brazilian interbank yield curve. Thus, we need the expectation for the one-day effective interbank interest rate $E_{t}\left[d_{t, k}\right]$, compounded from time $t$ to time $k$. The day counting practice in Brazil is based on working days, considering a year with 252 working days. Then we expressed the rate on an annualized basis:

$$
E_{t}\left[d_{t, k}\right]=\left(\prod_{i=t}^{k}\left(1+E_{t}\left[d_{i}\right]\right)\right)^{\frac{252}{k-t}}-1 .
$$

Where:

$E_{t}\left[d_{t, k}\right] \quad$ is the expected one-day effective interbank interest rate compounded from time $t$ to time $k$, and then expressed in annualized terms;

$E_{t}\left[d_{i}\right] \quad$ is the expectation, at time $t$, of the effective interbank rate for day $i$.

It is worth highlighting that $E_{t}\left[d_{i}\right]$ does not have to take into account any term premium because it considers only the expectation of the one-day interest rate behavior.

The survey has forecasts for the policy rate (the Selic rate), but not for the interbank rate. Therefore, we use the expectation for the policy rate Selic in order to build the expected one-day interbank interest rates $E\left[d_{i}\right]$ :

$$
E_{t}\left[g_{i}\right]=E_{t}\left[d_{i}\right]+E_{t}\left[s_{i}\right]
$$

Where:

$g_{i} \quad$ is the monetary policy target for the Selic interest rate for day $i$;

$E_{t}\left[g_{i}\right] \quad$ is the expectation, at time $t$, of the monetary policy target for the Selic interest rate for day $i$;

$E_{t}\left[s_{i}\right] \quad$ is the expectation, at time $t$, of the difference (spread) between the Selic target rate and the interbank effective rate for day $i$.

The expected Selic target rate $E_{t}\left[g_{i}\right]$ is taken from the survey of market expectations carried out by the Central Bank of Brazil at time $t$. We need the expected target rate for each day, but the actual forecast data is done 1 to 12 months ahead. It is worth remembering that the forecast is intended to be the target (and not the effective) interest rate at the end of the month. As the target rate only changes after the Copom meetings, we assume that, for each month $m$, for all days until the Copom meeting the expected target rate $E_{t}\left[g_{i}\right]$ is the one forecasted for the previous month $(m-1)$, and after the Copom meeting, we consider the forecasted target rate for that month $m$.

The expected difference, at time $t$, between the target rate and the effective interbank rate is estimated by simply taking the difference between the target Selic rate at time $t$ and the effective one-day interbank rate at time $t$ :

$$
E_{t}\left[s_{i}\right]=g_{t}-d_{t, 1}
$$

Eq. (A3) assumes that the current difference between the interbank effective rate and the Selic target rate is the best estimator for this difference in the future. This difference is reasonably stable. If this difference becomes very volatile, our term premium may experience an increase in the measurement error. The one-time level change as occurred in 2013 will affect our measure in just one day.

Eq. (A3) calculates the expected spread $E_{t}\left[s_{i}\right]$ given then the target Selic rate and the one-day interbank rate for a given day $t$. Then, we take this expected spread and the expected target Selic rate $E_{t}\left[g_{i}\right]$ to get the expected interbank rate $E_{t}\left[d_{i}\right]$ using Eq. (A2). Finally, we multiply the expected interbank rates for each day as in Eq. (A1), to get the expectation for the one-day effective interbank interest rate $E_{t}\left[d_{t, k}\right]$. 


\section{Appendix B. Tests for bias on survey forecasts}

If survey forecasts are used to calculate term premium, it is important to check for possible biases to ensure that no bias is included in our term premium calculation. Unfortunately, literature about forecast biases in Brazil tends to focus on inflation forecasts (see Carvalho and Minella, 2012). Therefore, we empirically test the unbiasedness of market surveys, considering changes in the monetary policy interest rates and survey forecasts on a daily basis. We tested the bias for the forecasts in each of the 86 Copom meetings in our sample with 1 day ahead and from 1 week to 52 weeks ahead. The one-day ahead is the mean forecast done on the Tuesday before the Copom meeting, which happens on Wednesdays. The one-week ahead is calculated with the forecast on the Friday before the Wednesday Copom meeting, and so on. This is done because the Friday forecasts are more visible due to the report published every Friday. Therefore, the one-week forecast is actually 5-days ahead, the two-week forecast is 12-days ahead and so on.

Table B.1 shows the mean and standard deviation of the forecast errors as well as the mean absolute error and the $t$ statistics for the null hypothesis that the forecast error is zero. We can see that the mean error oscillates from negative to positive with values under 3 basis points for forecasts up to 28 weeks. After that, the mean error is mainly positive, but under 20 basis points. In all cases, we cannot reject the null hypothesis that the forecast error is zero. Therefore, we have evidence that the forecasts are not biased.

Table B.1

Survey forecast errors.

\begin{tabular}{|c|c|c|c|c|c|c|c|c|c|}
\hline $\begin{array}{l}\text { Forecast } \\
\text { weeks } \\
\text { ahead }\end{array}$ & $\begin{array}{l}\text { Mean } \\
\text { error }\end{array}$ & $\begin{array}{l}\text { Standard } \\
\text { deviation } \\
\text { of error }\end{array}$ & $\begin{array}{l}\text { Mean } \\
\text { absolute } \\
\text { error }\end{array}$ & t-stat & $\begin{array}{l}\text { Forecast } \\
\text { weeks } \\
\text { ahead }\end{array}$ & $\begin{array}{l}\text { Mean } \\
\text { error }\end{array}$ & $\begin{array}{l}\text { Standard } \\
\text { deviation } \\
\text { of error }\end{array}$ & $\begin{array}{l}\text { Mean } \\
\text { absolute } \\
\text { error }\end{array}$ & t-stat \\
\hline 0 & 0.01 & 0.14 & 0.09 & 0.48 & 26 & 0.01 & 1.54 & 1.18 & 0.06 \\
\hline 1 & 0.01 & 0.15 & 0.09 & 0.38 & 27 & 0.02 & 1.62 & 1.25 & 0.11 \\
\hline 2 & 0.00 & 0.17 & 0.11 & 0.01 & 28 & 0.03 & 1.69 & 1.30 & 0.15 \\
\hline 3 & $(0.00)$ & 0.19 & 0.12 & $(0.06)$ & 29 & 0.06 & 1.74 & 1.34 & 0.33 \\
\hline 4 & $(0.01)$ & 0.23 & 0.15 & $(0.46)$ & 30 & 0.06 & 1.81 & 1.40 & 0.32 \\
\hline 5 & $(0.02)$ & 0.28 & 0.18 & $(0.64)$ & 31 & 0.03 & 1.89 & 1.47 & 0.14 \\
\hline 6 & $(0.02)$ & 0.32 & 0.22 & $(0.56)$ & 32 & 0.04 & 1.97 & 1.54 & 0.20 \\
\hline 7 & $(0.01)$ & 0.35 & 0.25 & $(0.18)$ & 33 & 0.09 & 2.02 & 1.59 & 0.42 \\
\hline 8 & $(0.01)$ & 0.42 & 0.30 & $(0.23)$ & 34 & 0.10 & 2.10 & 1.65 & 0.43 \\
\hline 9 & $(0.02)$ & 0.47 & 0.34 & $(0.44)$ & 35 & 0.06 & 2.17 & 1.71 & 0.26 \\
\hline 10 & $(0.02)$ & 0.51 & 0.37 & (0.39) & 36 & 0.06 & 2.23 & 1.76 & 0.26 \\
\hline 11 & $(0.01)$ & 0.54 & 0.40 & $(0.11)$ & 37 & 0.10 & 2.28 & 1.79 & 0.42 \\
\hline 12 & $(0.01)$ & 0.59 & 0.44 & $(0.14)$ & 38 & 0.12 & 2.34 & 1.84 & 0.46 \\
\hline 13 & $(0.02)$ & 0.68 & 0.51 & $(0.29)$ & 39 & 0.09 & 2.42 & 1.91 & 0.34 \\
\hline 14 & $(0.02)$ & 0.74 & 0.56 & $(0.24)$ & 40 & 0.10 & 2.49 & 1.96 & 0.38 \\
\hline 15 & $(0.02)$ & 0.79 & 0.60 & $(0.22)$ & 41 & 0.11 & 2.53 & 2.00 & 0.39 \\
\hline 16 & $(0.01)$ & 0.83 & 0.62 & $(0.09)$ & 42 & 0.15 & 2.57 & 2.03 & 0.53 \\
\hline 17 & $(0.01)$ & 0.90 & 0.67 & $(0.11)$ & 43 & 0.15 & 2.62 & 2.08 & 0.54 \\
\hline 18 & $(0.03)$ & 0.96 & 0.73 & $(0.29)$ & 44 & 0.12 & 2.67 & 2.13 & 0.43 \\
\hline 19 & $(0.02)$ & 1.02 & 0.78 & $(0.22)$ & 45 & 0.14 & 2.72 & 2.17 & 0.47 \\
\hline 20 & 0.01 & 1.08 & 0.82 & 0.10 & 46 & 0.15 & 2.76 & 2.20 & 0.51 \\
\hline 21 & 0.01 & 1.17 & 0.88 & 0.10 & 47 & 0.18 & 2.80 & 2.23 & 0.61 \\
\hline 22 & $(0.01)$ & 1.26 & 0.95 & $(0.04)$ & 48 & 0.19 & 2.84 & 2.26 & 0.61 \\
\hline 23 & 0.00 & 1.32 & 1.00 & 0.02 & 49 & 0.15 & 2.87 & 2.30 & 0.49 \\
\hline 24 & 0.03 & 1.37 & 1.04 & 0.23 & 50 & 0.19 & 2.89 & 2.31 & 0.61 \\
\hline 25 & 0.03 & 1.43 & 1.09 & 0.23 & 51 & 0.19 & 2.90 & 2.32 & 0.61 \\
\hline 26 & 0.01 & 1.54 & 1.18 & 0.06 & 52 & 0.17 & 2.94 & 2.36 & 0.54 \\
\hline
\end{tabular}

This table shows survey forecast errors for 86 Copom (Brazilian monetary policy committee) meetings in our sample with survey forecasts one day ahead and from one week to 52 weeks ahead. The one-week ahead error is calculated with forecast on the Friday before the Wednesday Copom meeting, and so on. The zero-week ahead forecast is the error one day before the meeting. The error is calculated by subtracting the interest rate set by Copom from survey forecast. The table shows the mean and standard deviation of errors as well as the mean absolute error and the $t$ statistics for the null hypothesis that error is equal to zero. 


\section{References}

Boudoukh, Jacob, Richardson, Matthew, Smith, Tom, Whitelaw, Robert F., 1999. Ex ante bond returns and the liquidity preference hypothesis. J. Financ. 54 (3), 1153-1167.

Campbell, John, Shiller, Robert, 1991. Yield spreads and interest rate movements: a bird's eye view. Rev. Econ. Stud. 58, 495-514.

Carvalho, Fabia A., Minella, André, 2012. Survey forecasts in Brazil: a prismatic assessment of epidemiology, performance, and determinants. J. Int. Money Financ. 31 (6), 1371-1391.

Cook, Timothy, Hahn, Thomas, 1990. Interest rate expectations and the slope of the money market yield curve. Economic Review. Federal Reserve Bank of Richmond, pp. 3-26 (issue September 1990).

Elton, Edwin, 1999. Expected return, realized return, and asset pricing tests. J. Financ. 54 (4), 1199-1220.

Engle, Robert F., Lilien, David M., Robins, Russell P., 1987. Estimating time varying risk premia in the term structure: the ARCH-M model. Econometrica 55 (2), 391-407.

Fama, Eugene F., 1984. Term premiums in bond returns. J. Financ. Econ. 13, 529-546.

Fama, Eugene F., 1986. Term premiums and default premiums in money markets. J. Financ. Econ. 17, 175-196.

Friedman, Benjamin M., 1979. Interest rate expectations versus forward rates: evidence from an expectations survey. J. Financ. 34 (4), 965-973 (September).

Froot, Kenneth A., 1989. New hope for the expectations hypothesis of the term structure of interest rates. J. Financ. 44 (2), 283-305.

Hardouvelis, Gikas, 1994. The term structure spread and future changes in long and short rates in the G7 countries - is there a puzzle? J. Monet. Econ. 33, 255-283.

Jongen, Ron, Verschoor, Willem F.C., Wolff, Christian C.P., 2011. Time-variation in term premia: international survey-based evidence. J. Int. Money Financ. 30 (4), 605-622 June.

Kessel, R., 1965. The cyclical behavior of the term structure of interest rates. NBER Occasional Paper 91.

Kim, Dom, Orphanides, Athanasios, 2007. The bond market term premium: what is it, and how can we measure it? BIS Q. Rev. 27-40 (June 2007).

Kim, Dom, Orphanides, Athanasios, 2012. Term structure estimation with survey data on interest rate forecasts. J. Financ. Quant. Anal. 47 (1), 241-272.

MacDonald, Ronald, Macmillan, Peter, 1994. On the expectations view of the term structure, term premia and survey-based expectations. Econ. J. Roy. Econ. Soc. 104 (426), 1070-1086.

McCulloch, J. Huston, 1975. An estimate of the liquidity premium. J. Polit. Econ. 83 (1)

McCulloch, J. Huston, 1987. The monotonicity of the term premium: a closer look. J. Financ. Econ. 18, 185-192.

Newey, Whitney, West, Kenneth D., 1987. A simple, positive semi-definite heteroskedasticity and autocorrelation consistent covariance matrix. Econometrica 55, 703-708.

Patton, Andrew, Timmermann, Allan, 2010. Monotonicity in asset returns: new tests with applications to the term structure, the CAPM, and portfolio sorts. J. Financ. Econ. 98, 605-625.

Politis, Dimitris N., Romano, Joseph R., 1994. The stationary bootstrap. Am. Stat. Assoc. 89 (428), 1303-1313.

Richardson, Mathew, Richardson, Paul, Smith, Tom, 1992. The monotonicity of the term premium: another look. J. Financ. Econ. 31, 97-106.

Swanson, Eric, 2007. What We Do and Don't Know About the Term Premium. Federal Reserve Bank of San Francisco Economic Letter.

Wolak, Frank, 1989. Local and global testing of linear and nonlinear inequality constraints in nonlinear econometric models. Econ. Theory 5, 1-35. 